researchers intending to replicate experiments.

The risk of a pandemic caused by an avian influenza virus exists in nature. As members of the influenza research community, we believe that the avian A(H7N9) virus outbreak requires focused fundamental and applied research conducted by responsible investigators with appropriate facilities and risk-mitigation plans in place. To answer key questions important to public health, research that may result in GOF is necessary and should be done.

Ron A. M. Fouchier ${ }^{\star}$ Erasmus Medical Center, Rotterdam, the Netherlands.

r.fouchier@erasmusmc.nl

Yoshihiro Kawaoka* University of Wisconsin-Madison,

Wisconsin, USA.

kawaokay@svm.vetmed.wisc.edu ${ }^{*}$ On behalf of 22 co-authors (see go.nature.com/fstdy1 for full list).

\section{Extra oversight for H7N9 experiments}

The US Department of Health and Human Services (HHS) announces a new review process for certain gain-of-function (GOF) experiments on the avian influenza A (H7N9) virus, some of which are proposed this week by influenza scientists (R. A. M. Fouchier et al. Nature 500, 150-151; 2013).

Specifically, before being undertaken using HHS funds, any experiments that are reasonably anticipated to generate $\mathrm{H} 7 \mathrm{~N} 9$ viruses with increased transmissibility between mammals by respiratory droplets will undergo an additional level of review by the HHS.

The HHS review will consider the acceptability of these experiments in light of potential scientific and public-health benefits as well as biosafety and biosecurity risks, and will identify any additional risk-mitigation measures needed. The review will be carried out by a standing multidisciplinary panel of federal experts with backgrounds in public health, medicine, security, science policy, global health, risk assessment, US law and ethics.

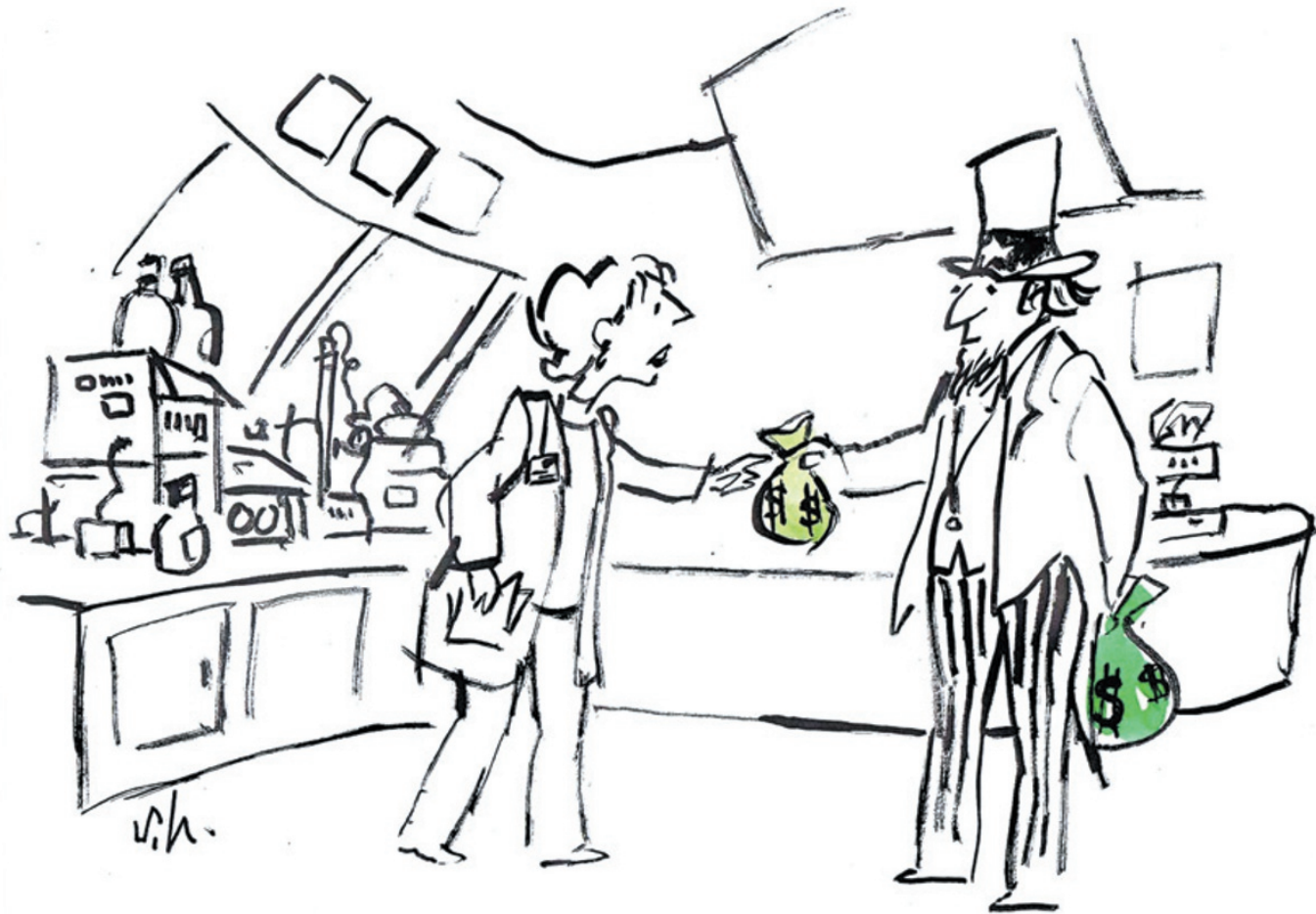

This approach, similar to that for certain $\mathrm{H} 5 \mathrm{~N} 1$ influenza virus experiments (see go.nature. com/vpmplf), allows the HHS to focus special oversight efforts on experiments of concern while allowing routine characterization and other fundamental research to proceed rapidly, thereby enabling a robust public-health response.

GOF studies can provide important insights into how the $\mathrm{A}(\mathrm{H} 7 \mathrm{~N} 9)$ virus adapts to mammalian hosts, causes disease and spreads to other hosts, but they may also pose biosafety and biosecurity risks. To ensure that research involving H7N9 virus is conducted safely and securely, the US Centers for Disease Control and Prevention recently re-examined the requisite biosafety conditions for conducting experiments involving H7N9 and, in June 2013, issued interim riskassessment and biosafety-level recommendations (see go.nature. com/gknn9a).

Harold W. Jaffe Centers for Disease Control and Prevention, Atlanta, Georgia, USA. Amy P. Patterson National Institutes of Health, Bethesda, Maryland, USA. pattersa@od.nih.gov Nicole Lurie Department of Health and Human Services, Washington DC, USA.

\section{Follow Obama's lead and take a pay cut}

In considering the impact of the US budget sequester on science (see, for example, Nature 499, 147-148; 2013), I see no mention of salary reductions. A 5\% reduction in the salaries of federally supported science staff, including administrative and agency personnel, would significantly reduce the need to cut science programmes.

US scientists are not paupers: NASA scientists, for instance, are paid up to US $\$ 160,000$ a year, with generous fringe benefits. Plenty of professors at leading US universities make much more. A 5\% cut to 12 -month and summer salaries would not leave anyone destitute.

Such a reduction would be much more effective than any presentations to Congress in showing that scientists care about their projects and are willing to share the pain of bringing US federal expenditure under control.

I doubt that any scientist would refuse to accept a grant offered on the proviso that the salary rate be reduced by $5 \%$, if the alternative were no grant at all. President Barack Obama took a pay cut to show the way.
Let's follow his lead. Peter Foukal Nahant, Massachusetts, USA. pvfoukal@comcast.net

\section{Three reasons for eco-label failure}

The fisheries industry promotes third-party eco-labels that signify sustainability, similar to those used in forestry and tourism (see Nature http://doi. org/nb5; 2013). In my view, these fail for three reasons.

First, consumers care strongly that labels for health and quality standards are accurate because they affect individuals, but care much less about eco-labels because their effects are spread across society.

Second, industries tend to use weak eco-labels in political games to avoid strong regulation.

Third, ineffective eco-labels closely mimic accurate ones. Because there are no adverse consequences for consumers who cannot tell them apart, a high proportion of mimics persists.

Eco-labels are thus no substitute for eco-laws. Ralf Buckley Griffith University, Gold Coast, Queensland, Australia. r.buckley@griffith.edu.au 